\title{
Estimation of rice phenology date using integrated HJ-1 CCD and Landsat-8 OLI vegetation indices time-series images"
}

\author{
Jing $\mathrm{WANG}^{1}$, Jing-feng $\mathrm{HUANG}^{1}$, Xiu-zhen $\mathrm{WANG}^{2}$, Meng-ting $\mathrm{JIN}^{2}$, Zhen ZHOU ${ }^{1}$, Qiao-ying GUO ${ }^{1}$, \\ Zhe-wen $\mathrm{ZHAO}^{1}$, Wei-jiao HUANG ${ }^{1}$, Yao ZHANG ${ }^{1}$, Xiao-dong $\mathrm{SONG}^{\dagger+1}$ \\ $\left({ }^{1}\right.$ Institute of Remote Sensing and Information Application, College of Environmental and \\ Resource Sciences, Zhejiang University, Hangzhou 310058, China) \\ ( ${ }^{2}$ Institute of Remote Sensing and Earth Sciences, Hangzhou Normal University, Hangzhou 311121, China) \\ †E-mail: xdsongy@zju.edu.cn \\ Received Apr. 15, 2015; Revision accepted Sept. 14, 2015; Crosschecked Sept. 17, 2015
}

\begin{abstract}
Accurate estimation of rice phenology is of critical importance for agricultural practices and studies. However, the accuracy of phenological parameters extracted by remote sensing data cannot be guaranteed because of the influence of climate, e.g. the monsoon season, and limited available remote sensing data. In this study, we integrate the data of HJ-1 CCD and Landsat-8 operational land imager (OLI) by using the ordinary least-squares (OLS), and construct higher temporal resolution vegetation indices (VIs) time-series data to extract the phenological parameters of single-cropped rice. Two widely used VIs, namely the normalized difference vegetation index (NDVI) and 2-band enhanced vegetation index (EVI2), were adopted to minimize the influence of environmental factors and the intrinsic difference between the two sensors. Savitzky-Golay (S-G) filters were applied to construct continuous VI profiles per pixel. The results showed that, compared with NDVI, EVI2 was more stable and comparable between the two sensors. Compared with the observed phenological data of the single-cropped rice, the integrated VI time-series had a relatively low root mean square error (RMSE), and EVI2 showed higher accuracy compared with NDVI. We also demonstrate the application of phenology extraction of the single-cropped rice in a spatial scale in the study area. While the work is of general value, it can also be extrapolated to other regions where qualified remote sensing data are the bottleneck but where complementary data are occasionally available.
\end{abstract}

Key words: Phenological parameters, Intercalibration, Vegetation index, HJ-1 CCD, Landsat-8 OLI doi: $10.1631 /$ jzus.B1500087

Document code: A

CLC number: S511

\section{Introduction}

Dynamic variation of regional crop phenology is an important component of agriculture monitoring (Eerens et al., 2014), and is of increasing relevance for environmental monitoring, e.g. changes in the

\footnotetext{
${ }^{\ddagger}$ Corresponding author

* Project supported by the National High-Tech R \& D Program (863) of China (No. 2012AA12A30703) and the Fundamental Research Funds for the Central Universities, China

(1) ORCID: Xiao-dong SONG, http://orcid.org/0000-0003-4174-7162

(c) Zhejiang University and Springer-Verlag Berlin Heidelberg 2015
}

phenological period and length of the growing season may be caused by climate variability (Brown and de Beurs, 2008; Pan et al., 2015). China has about one fifth of the world's paddy rice land, and it is of critical importance to extract the phenology information of rice on a large spatial scale to serve related research in agricultural modeling, yield estimation, and climate change (FAOSTAT, 2012; Li S.H. et al., 2014).

Remote sensing techniques offer a feasible tool for delineating spatiotemporal patterns of crop status on a per-pixel basis. Various kinds of optical remote sensing data and techniques have been applied in agricultural monitoring, e.g. the Advanced Very High 
Resolution Radiometer (AVHRR), the Moderate Resolution Imaging Spectroradiometer (MODIS), and the Systeme Probatoire d'Observation de la Terre (SPOT) VEGETATION (Wu et al., 2010; Peng et al., 2011; Cong et al., 2012; Lanorte et al., 2014). However, the spectral characteristics of the data may be seriously affected by a mixed-pixel problem due to the relative coarse resolutions $(\geq 250 \mathrm{~m}$ ) (Sakamoto et al., 2005). The Landsat remote sensing data have relatively high spatial resolution but, hampered by its low-temporal resolution, are not suitable for phenological information extraction purposes in agriculture (Anderson et al., 2011). When considering the influence of climate, the situation may be more serious. Most of the paddy fields located in the subtropical regions of China are influenced by the monsoon climate; as a consequence, the qualifying cloud-free remote sensing data during this monsoon period are relatively few (Pyongsop et al., 2010; Cai et al., 2012). To accurately extract the phenological information of rice in this region, a high spatial and temporal resolution remote sensing dataset is required, especially during the biologically sensitive growing period ( $\mathrm{Wu}$ et al., 2010).

The small sun-synchronous satellites for environment and disaster monitoring and forecasting (HJ-1A and HJ-1B) from China were launched in 2008. The HJ-1A/B satellites have swath width of $700 \mathrm{~km}$, four spectral bands with a spatial resolution of $30 \mathrm{~m}$ in the visible bands, and a revisit cycle of four days (the revisit cycle of the constellation is two days) as shown in Table 1 (She et al., 2015). The sensor characteristics of HJ-1 CCD and Landsat-8 operational land imagers (OLIs), including the visible bands composition and spatial resolution, are very comparable. The Landsat- 8 was launched on February 2013, and our intent is to combine HJ-1 CCD and Landsat-8 OLI data and verify its capability for extracting the phenological information of the singlecropped rice in southern China.

The time-series vegetation indices (VIs), such as the normalized difference vegetation index (NDVI) (Rouse et al., 1974) and the 2-band enhanced vegetation index (EVI2) (Jiang et al., 2007), are widely used in the studies of crop land classification, plant productivity, phenology, and crop growth monitoring (Panda et al., 2010; Gao et al., 2013; Shi et al., 2013; Zhang et al., 2013). It has been shown that VIs are
Table 1 Sensor characteristics of HJ-1 CCD and Landsat-8 OLI

\begin{tabular}{lcc}
\hline \multicolumn{1}{c}{ Characteristic } & HJ-1 CCD & Landsat-8 OLI \\
\hline Altitude $(\mathrm{km})$ & 649 & 705 \\
Repetition cycle (d) & 31 & 16 \\
Revisit interval (d) & 4 (2 for constellation) & 16 \\
Scanning technique & Push-broom & Push-broom \\
Swath width (km) & 360 (700 for two) & 185 \\
FOV $\left(^{\circ}\right)$ & $0-35$ & 15 \\
Band $(n)$ & 4 & 9 \\
Resolution $(\mathrm{m})$ & 30 & 15 (Pan), 30 \\
Spectral interval $(\mu \mathrm{m})$ & & \\
B1-Blue & $0.43-0.52$ & $0.45-0.51$ \\
B2-Green & $0.52-0.60$ & $0.53-0.59$ \\
B3-Red & $0.63-0.69$ & $0.64-0.67$ \\
B4-NIR & $0.76-0.90$ & $0.85-0.88$ \\
\hline
\end{tabular}

FOV: field of view; NIR: near infrared; Pan: panchromatic band

relatively insensitive to the differences in angular viewing factors and atmospheric disturbances and thereby can be used as a benchmark for direct comparison between sensors (Steven et al., 2003).

Regression analysis has been common practice for the intercalibration of different remote sensing data. The ordinary least-squares (OLS) model is a primary tool for comparing two datasets and predicting one dataset from another (Ji et al., 2008). Anderson et al. (2011) compared the ResourceSat-1 NDVI values and Landsat-5 NDVI values by building an intercalibration equation. Li P. et al. (2014) used OLS in cross-comparison of VIs derived from Landsat-8 OLI and Landsat-7 Enhanced Thematic Mapper Plus (ETM + ) sensors, and showed that OLI and ETM+ data are complementary. Agreement assessment is another important research topic in image intercalibration. The non-dimensional and symmetrical features of some agreement measures are more suitable for intercalibrating the VIs acquired from different sensors (Mielke and Berry, 2001; Ji and Gallo, 2006). In agreement analysis, the two datasets are treated equally and symmetrically, and the systematic and unsystematic differences between two datasets can be quantified. The geometric mean (GM) regression, orthogonal regression, and OLS bisector regression are widely used symmetrical regression models (Sprent and Dolby, 1980; Isobe et al., 1990; Rawlings et al., 1990; Valsami and Macheras, 1995). Ji et al. (2008) used agreement analysis using symmetrical regression models and compared the 
AVHRR and MODIS 16-d composite NDVI products. GM regression-based agreement analysis was also used in a cross-sensor comparison study between Landsat-5 TM and IRS-P6 AWiFS (Chen et al., 2013).

The goal of this study was to generate a new VI time-series data with a higher temporal resolution by integrating HJ-1 CCD and Landsat-8 OLI images, in order to extract the phenological information of the single-cropped rice more accurately, and verify that VIs derived from HJ CCD and OLI images can be used as complementary data after proper intercalibration. We used the OLS method to integrate the two remote sensing datasets with the aid of a field campaign, and compared the efficiencies of NDVI and EVI2 using the agreement analysis technique. We also evaluated the integrated time-series VIs in rice phenological parameter extraction using field survey data.

\section{Data and methods}

\subsection{Study area}

Deqing County located in North Zhejiang Province was selected as the study area. It has a mean annual temperature ranging from 13 to $16{ }^{\circ} \mathrm{C}$ and annual precipitation of $1379 \mathrm{~mm}$ (Fig. 1). This region is dominated by the tropical monsoon climate and more than $91 \%$ of the crop area is single-cropped rice, according to local statistical data.
According to a field survey conducted during 2013-2014, the land cover types were classified as rice, trees, water bodies, artificial surfaces, and others. Four typical testing sites were selected with different land cover structures to intercalibrate the VIs derived from the two sensors. All testing sites were larger than $4 \mathrm{~km} \times 4 \mathrm{~km}$. Furthermore, total 2281 independent randomly selected sample points were used for comparison based on the field survey and the Second National Soil Survey Vector Map, in which there were 484 for rice, 434 for trees, 709 for water bodies, 448 for artificial surfaces, and 206 for other areas. Sixteen site-based observations of rice phenology in 2013 provided by the Deqing agro-meteorological station were used as validation.

\subsection{Satellite data}

The HJ-1 CCD sensors have similar characteristics to the Landsat-8 OLI, including a nominal descending orbit at 10:30 a.m. local crossing time, the same spatial resolution of $30 \mathrm{~m}$, and overlapped bands in the visible spectrum (Fig. 1; Table 1). The prominent short revisit interval of HJ-1 CCD makes it an ideal candidate for crop status monitoring.

We followed three basic principles in selecting remote sensing images of HJ-1 CCD and OLI in the study area to meet the requirement of calibration and time-series VI construction. They were that (1) the acquisition time difference of HJ-1 CCD and OLI

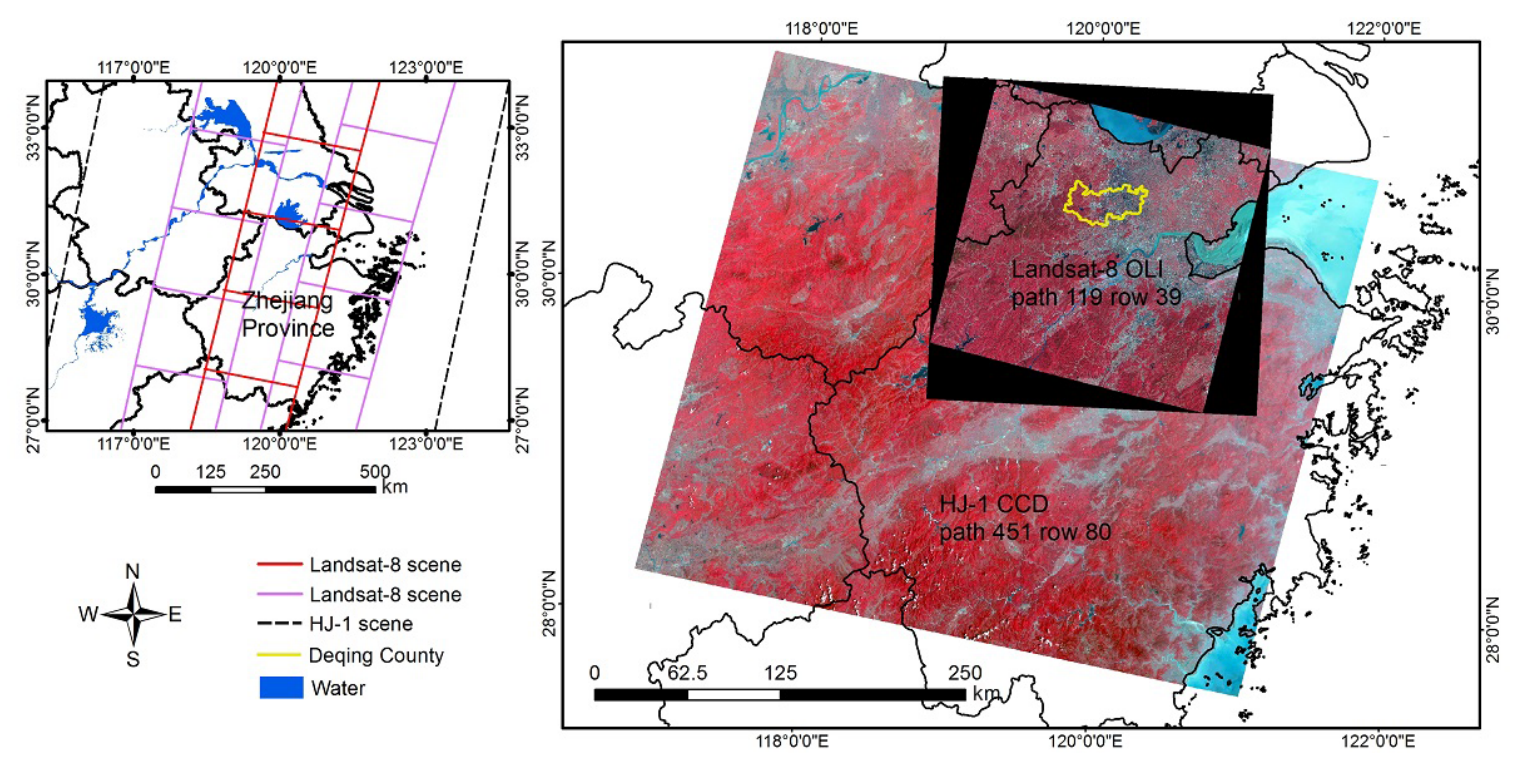

Fig. 1 Map of the study area

Two overlaid images are HJ-1B CCD1 (path 451 row 80) and Landsat-8 OLI (path 119 row 39), respectively. Dashed line refers to the HJ-1 CCD scene and the solid line refers to the Landsat-8 OLI scene (the swath width of each constellation) 
should be within one day; (2) the time span of the remote sensing dataset should cover the whole growing season of the single-cropped rice; and (3) all the four testing sites should be cloud-free in the image pairs for calibration.

Six pairs of archived HJ-1 CCD and Landsat- 8 OLI data less than one day apart covering the study area in 2013 and 2014 were collected for intercalibration purposes (Table 2). To extract the rice phenological information, all the 32 relatively cloud-free $\mathrm{HJ}-1$ CCD and OLI images which covered the rice growing period (from late May to early December) in 2013 were also collected to construct the time-series VIs (Table 3 ).

The Level 2 HJ-1 CCD images were downloaded from the China Centre for Resources Satellite Data and Application (CRESDA). The Landsat-8 OLI standard level-one terrain-corrected (L1T) products were collected from the US Geological Survey (USGS). The OLI L1T products were geometrically corrected and orthorectified products by the data provider using standard systematic correction methods.

\subsection{Pro-processing and VI calculation}

The images used were all processed by the radiometric calibration first. The formula and coefficients were collected from the raw data package. The atmospheric correction was performed using the Moderate Resolution Transmission (MODTRAN) 4 model integrated in FLAASH module in the ENVI package. The images were geometrically corrected using geographic information system (GIS) data to an accuracy less than 0.5 pixel $(15 \mathrm{~m})$.

Table 2 Image pairs of HJ-1 CCD and Landsat-8 OLI used for calibration

\begin{tabular}{clccccc}
\hline \multirow{2}{*}{ Pair } & \multicolumn{1}{c}{ Sensor } & $\begin{array}{c}\text { Acquisition date } \\
\text { (year/month/day) }\end{array}$ & $\begin{array}{c}\text { Scene center scan time } \\
(\mathrm{GMT})\end{array}$ & Path/row & $\begin{array}{c}\text { Sun elevation } \\
\left({ }^{\circ}\right)\end{array}$ & $\begin{array}{c}\text { Sun azimuth } \\
\left({ }^{\circ}\right)\end{array}$ \\
\hline 1 & HJ-1B CCD1 & $2013 / 04 / 14$ & $02: 06: 46$ & $448 / 80$ & 58.01 & 302.94 \\
& Landsat-8 OLI & $2013 / 04 / 14$ & $02: 33: 23$ & $119 / 39$ & 61.02 & 131.11 \\
2 & HJ-1B CCD2 & $2013 / 07 / 18$ & $01: 46: 37$ & $448 / 80$ & 59.57 & 279.88 \\
& Landsat-8 OLI & $2013 / 07 / 19$ & $02: 33: 33$ & $119 / 39$ & 67.17 & 108.62 \\
\multirow{2}{*}{3} & HJ-1A CCD1 & $2013 / 08 / 05$ & $02: 07: 42$ & $451 / 80$ & 60.86 & 289.65 \\
& Landsat-8 OLI & $2013 / 08 / 04$ & $02: 33: 35$ & $119 / 39$ & 65.27 & 116.26 \\
\multirow{2}{*}{4} & HJ-1A CCD1 & $2013 / 11 / 09$ & $01: 56: 45$ & $450 / 80$ & 34.85 & 323.72 \\
& Landsat-8 OLI & $2013 / 11 / 08$ & $02: 33: 19$ & $119 / 39$ & 40.30 & 157.66 \\
5 & HJ-1A CCD1 & $2013 / 12 / 10$ & $01: 56: 09$ & $451 / 80$ & 29.44 & 326.70 \\
& Landsat-8 OLI & $2013 / 12 / 10$ & $02: 33: 10$ & $119 / 39$ & 33.61 & 157.88 \\
6 & HJ-1B CCD2 & $2014 / 01 / 27$ & $01: 39: 26$ & $451 / 80$ & 30.06 & 319.56 \\
& Landsat-8 OLI & $2014 / 01 / 27$ & $02: 32: 41$ & $119 / 39$ & 35.73 & 150.42 \\
\hline
\end{tabular}

GMT: Greenwich mean time. Sun azimuth of $\mathrm{HJ}$ ranges from $0^{\circ}$ to $360^{\circ}$, while for Landsat- 8 the range is from $-180^{\circ}$ to $180^{\circ}$

Table 3 Images of HJ-1 CCD and Landsat-8 OLI used for phenology extraction

\begin{tabular}{clc||ccc}
\hline No. & Sensor & $\begin{array}{c}\text { Acquisition date } \\
\text { (year/month/day) }\end{array}$ & No. & Sensor & $\begin{array}{c}\text { Acquisition date } \\
\text { (year/month/day) }\end{array}$ \\
\hline 1 & HJ-1B CCD2 & $2013 / 05 / 14$ & 17 & HJ-1A CCD2 & $2013 / 08 / 16$ \\
2 & HJ-1A CCD2 & $2013 / 05 / 20$ & 18 & HJ-1B CCD2 & $2013 / 08 / 18$ \\
3 & HJ-1A CCD1 & $2013 / 05 / 28$ & 19 & Landsat-8 OLI & $2013 / 08 / 20$ \\
4 & HJ-1B CCD2 & $2013 / 06 / 06$ & 20 & HJ-1A CCD1 & $2013 / 09 / 01$ \\
5 & Landsat-8 OLI & $2013 / 06 / 17$ & 21 & HJ-1A CCD2 & $2013 / 09 / 04$ \\
6 & Landsat-8 OLI & $2013 / 07 / 03$ & 22 & HJ-1B CCD1 & $2013 / 09 / 26$ \\
7 & HJ-1A CCD1 & $2013 / 07 / 05$ & 23 & HJ-1A CCD1 & $2013 / 10 / 11$ \\
8 & HJ-1A CCD1 & $2013 / 07 / 09$ & 24 & HJ-1A CCD2 & $2013 / 10 / 20$ \\
9 & HJ-1B CCD1 & $2013 / 07 / 11$ & 25 & Landsat-8 OLI & $2013 / 10 / 23$ \\
10 & HJ-1B CCD2 & $2013 / 07 / 18$ & 26 & HJ-1A CCD2 & $2013 / 10 / 28$ \\
11 & Landsat-8 OLI & $2013 / 07 / 19$ & 27 & Landsat-8 OLI & $2013 / 11 / 08$ \\
12 & HJ-1A CCD2 & $2013 / 07 / 24$ & 28 & HJ-1A CCD1 & $2013 / 11 / 09$ \\
13 & HJ-1B CCD1 & $2013 / 07 / 30$ & 29 & HJ-1A CCD2 & $2013 / 11 / 16$ \\
14 & Landsat-8 OLI & $2013 / 08 / 04$ & 30 & HJ-1A CCD2 & $2013 / 11 / 20$ \\
15 & HJ-1A CCD1 & $2013 / 08 / 05$ & 31 & HJ-1A CCD2 & $2013 / 11 / 28$ \\
16 & HJ-1A CCD2 & $2013 / 08 / 12$ & 32 & HJ-1A CCD1 & $2013 / 12 / 02$ \\
\hline
\end{tabular}


Two widely used VIs, i.e. NDVI and EVI2, were selected as the candidates to construct the time-series VI for extracting the phenological information of the single-cropped rice. The NDVI has been proved to be one of the best indicators for vegetation status monitoring (Xie et al., 2008). While for EVI2, compared with EVI, it is more stable across sensors because only 2 bands are used (Jiang et al., 2007; 2008; Kim et al., 2010; Wang et al., 2015). The corresponding formulas are given as follows:

$$
\begin{gathered}
\text { NDVI }=\frac{\rho_{\text {nir }}-\rho_{\text {red }}}{\rho_{\text {nir }}+\rho_{\text {red }}}, \\
\text { EVI2 }=2.5 \times \frac{\rho_{\text {nir }}-\rho_{\text {red }}}{\rho_{\text {nir }}+2.4 \times \rho_{\text {red }}+1},
\end{gathered}
$$

where $\rho_{\text {red }}$ and $\rho_{\text {nir }}$ refer to the surface reflectance values of Bands 3 and 4 in HJ-1 CCD sensors, and Bands 4 and 5 in Landsat-8 OLI sensors, respectively (Table 1).

\subsection{Regression and agreement analysis}

For intercalibration, we built the OLS regression functions and transformed Landsat-8 OLI-VIs to HJ-1 CCD-VIs based on the data of the four typical testing sites. The GM regression results were used in the following agreement analysis.

The agreement metric, i.e. the agreement coefficient (AC), proposed by Ji and Gallo (2006) was adopted to evaluate the agreement of the two datasets. The $\mathrm{AC}$ has the properties to distinguish between systematic and unsystematic differences. The $\mathrm{AC}$ is defined as:

$$
\mathrm{AC}=1-\frac{\sum_{i=1}^{n}\left(X_{i}-Y_{i}\right)^{2}}{\sum_{i=1}^{n}\left(|\bar{X}-\bar{Y}|+\left|X_{i}-\bar{X}\right|\right)\left(|\bar{X}-\bar{Y}|+\left|Y_{i}-\bar{Y}\right|\right)},
$$

where $\bar{X}$ and $\bar{Y}$ are the mean values of datasets $X$ and $Y$, respectively. $X_{i}$ and $Y_{i}$ are the VI values of each pixel $(i=1,2,3, \ldots, n)$. The agreement between $X$ and $Y$ increases as AC approaches 1, and vice versa.

The mean square difference (MSD), a metric used to measure the systematic and unsystematic differences between two dataset, is defined as:

$$
\operatorname{MSD}=\frac{1}{n} \sum_{i=1}^{n}\left(X_{i}-Y_{i}\right)^{2}
$$

The MSD can be further divided into the unsystematic mean product-difference $\left(\mathrm{MPD}_{\mathrm{u}}\right)$ and systematic mean product-difference $\left(\mathrm{MPD}_{\mathrm{s}}\right)$. The $\mathrm{MPD}_{\mathrm{u}}$ is as follows:

$$
\operatorname{MPD}_{\mathrm{u}}=\frac{1}{n} \sum_{i=1}^{n}\left(\left|X_{i}-\hat{X}_{i}\right|\right)\left(\left|Y_{i}-\hat{Y}_{i}\right|\right)
$$

where $\hat{X}_{i}$ and $\hat{Y}_{i}$ are the predicted $X$ and $Y$ values, estimated by the GM and inverse GM regressions, respectively. The $\mathrm{MPD}_{\mathrm{s}}$ is then defined as follows:

$$
\mathrm{MPD}_{\mathrm{s}}=\mathrm{MSD}-\mathrm{MPD}_{\mathrm{u}}
$$

To compare the difference properties, i.e. the systematic and unsystematic differences, between the two datasets, we also calculated $\mathrm{MPD}_{\mathrm{s}} / \mathrm{MSD}$ and $\mathrm{MPD}_{\mathrm{u}} / \mathrm{MSD}$, expressed as percentages.

\subsection{Rice phenological parameters extracted by time-series VIs}

To evaluate the performance of time-series VIs produced by HJ-1 CCD and OLI sensors in rice phenological parameter extraction, we constructed two VI time-series for NDVI and EVI2, respectively. The 1st time-series VI was produced using HJ-1 CCD alone; and the 2nd one was generated by integrating HJ-1 CCD and OLI data. The Savitzky-Golay (S-G) filters were applied to smooth the VI time-series data to reduce the undesirable noise caused by unfavorable fluctuations (Jönsson and Eklundh, 2004; Hird and McDermid, 2009; Pan et al., 2015). Readers interested in the S-G filters are referred to these studies (Jönsson and Eklundh, 2004; Hird and McDermid, 2009) for more details. The S-G filters were applied to the image-based VI time-series data composed by the HJ-1CCD and Landsat-8 OLI data from late May to early December in 2013 as listed in Table 3.

Before phenological parameters extraction, the planting area of single-cropped rice was estimated using a stepwise classification strategy proposed by Wang et al. (2015). The total acreage of the singlecropped rice was about $94.0 \mathrm{~km}^{2}$ in 2013 , mainly distributed in the eastern part of the study area. 
Individual phenological stages of crops are identified by considering the VI increment or decrement between consecutive images over a certain period of time (Xin et al., 2002; Boschetti et al., 2009) (Fig. 2). Divided by the heading date, the growth phases of single-cropped rice can be classified into vegetative growth and reproductive growth. Because the maximum VI usually appears around the heading date, it is convenient to define the heading date as the date of the maximum VI on the VI profile. In general, the rice fields are flooded before transplanting and the $\mathrm{VI}$ of rice fields decreases during this period and then increases after rice planting. Therefore, it is reasonable to define the transplanting date of rice as the minimal point along the VI profile. Due to the etiolation and senescence of the rice leaves, the VI decreases after the heading, and the maturation date of rice is identified by the maximum slope method ( $\mathrm{Yu}$ et al., 2003; You et al., 2013). The results were validated with the field survey data collected by the local agro-meteorological station in 2013.

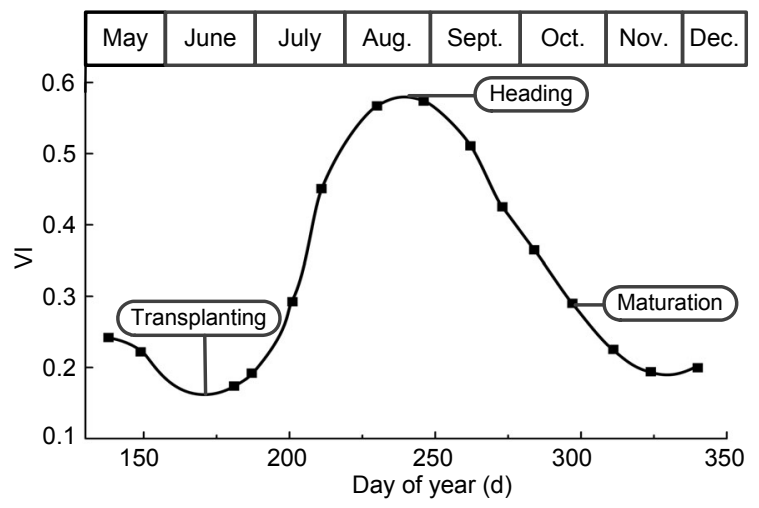

Fig. 2 VI profile of the single-cropped rice Smooth curve was generated using S-G filters

\section{Results}

\subsection{Intercalibration of VIs}

We first compared the VI values of different land cover types of the sample points derived from HJ-1 CCD and Landsat-8 OLI images. It showed that EVI2 was more stable and comparable between the two sensors compared with NDVI (Fig. 3). This was further illustrated by the relatively small standard deviation of EVI2. The fluctuations of mean values of EVI2 were less than 0.04 while those of NDVI were around 0.05 .
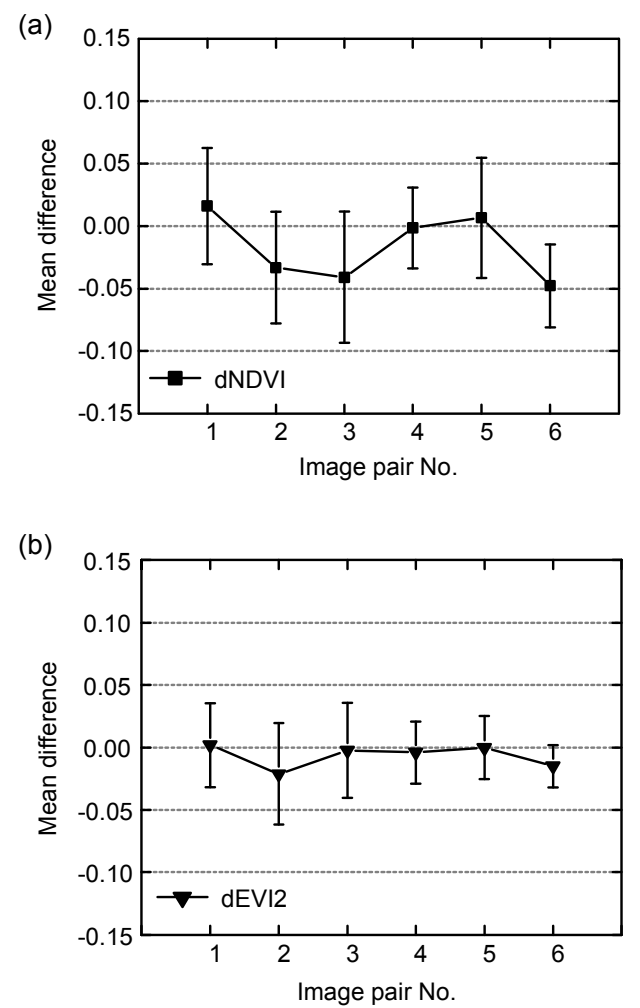

Fig. 3 Mean values and standard deviations of the differenced vegetation indices

dNDVI: differenced NDVI; dEVI2: differenced EVI2. dNDVI (a) and dEVI2 (b) are derived from Landsat-8 OLI and HJ-1 CCD images (image pair No. represents the six images pairs listed in Table 2)

The linear regression relationships between Landsat-8 OLI-VIs and HJ-1 CCD-VIs for all samples (pixels) in the testing sites are shown in Fig. 4. The two datasets are highly correlated for both NDVI and EVI2. The coefficients of determination of NDVI and EVI2 were 0.871 and 0.891 , respectively.

The agreement analysis showed that NDVI and EVI2 both had relatively high AC values ( 0.87 for NDVI and 0.89 for EVI2; Table 4). It's notable that the $\mathrm{MPD}_{\mathrm{u}}$ values were much higher than the $\mathrm{MPD}_{\mathrm{s}}$ values for both VIs, indicating that the unsystematic difference was greater than the systematic difference. Additionally, the $\mathrm{MPD}_{\mathrm{u}} / \mathrm{MSD}$ values were much higher than $\mathrm{MPD}_{\mathrm{s}} / \mathrm{MSD}$ values for both VIs, an indication that the unsystematic difference was the primary difference between the two datasets. The $M P D_{s}$ and $M P D_{u}$ values of EVI2 were lower than those of NDVI, and it appeared that HJ-1 CCD and Landsat OLI may have more consistency in using EVI2. 

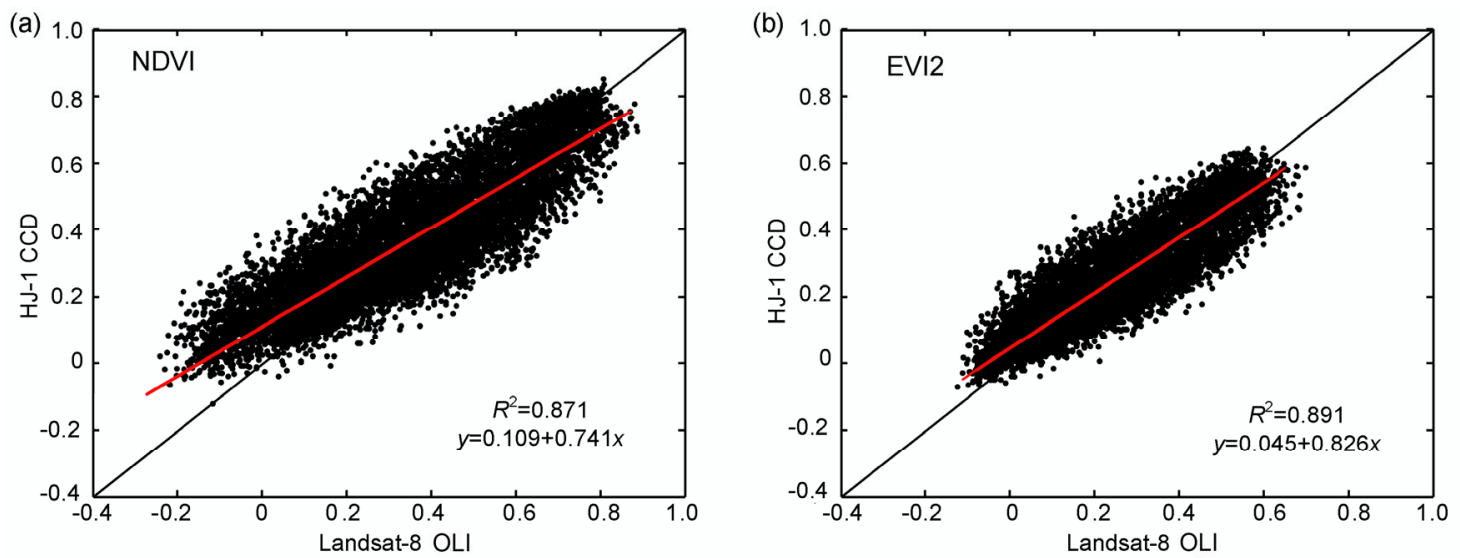

Fig. 4 Regression analysis of HJ-1 CCD-VIs versus Landsat-8 OLI-VIs using data of the four testing sites within six image pairs

Black solid lines are the $45^{\circ}$ lines and red solid lines are the linear regression trendlines (Note: for interpretation of the references to color in this figure legend, the reader is referred to the web version of this article)
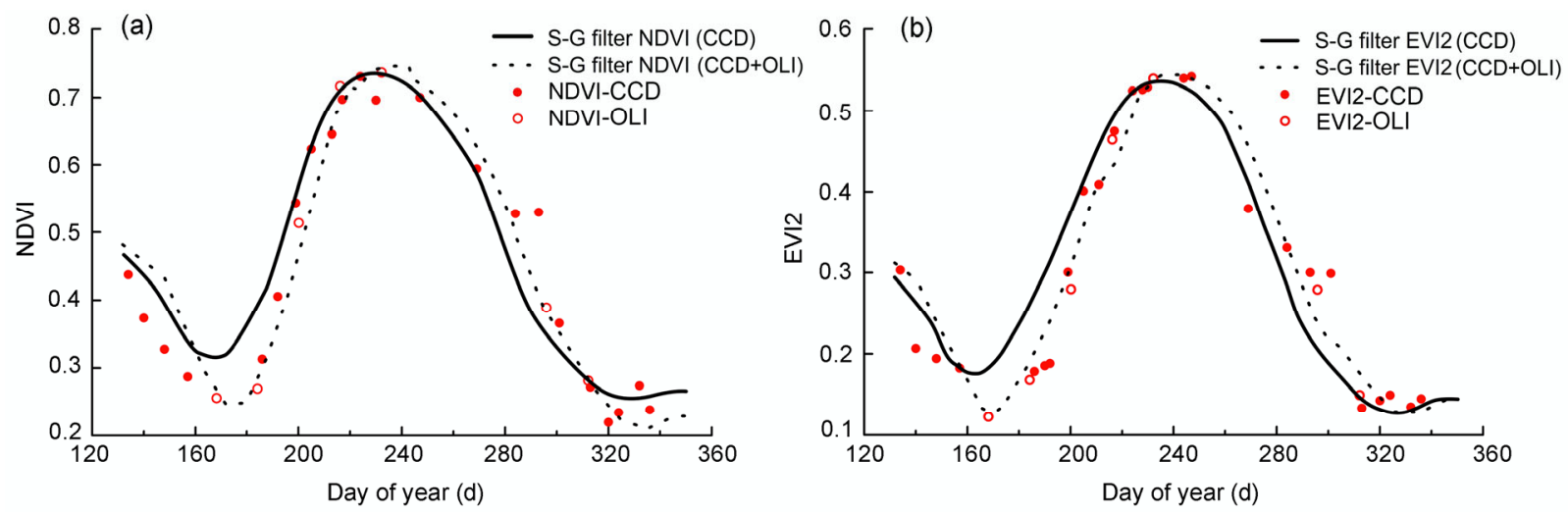

Fig. 5 VI time-series generated by Savitzky-Golay filters

Table 4 Agreement analysis for HJ-1 CCD-VIs (variable $Y$ ) and Landsat-8 OLI-VIs (variable $X$ )

\begin{tabular}{lcccccc}
\hline \multicolumn{1}{c}{ VI } & $\mathrm{AC}$ & $\mathrm{MSD}\left(\times 10^{-3}\right)$ & $\mathrm{MPD}_{\mathrm{s}}\left(\times 10^{-3}\right)$ & $\mathrm{MPD}_{\mathrm{u}}\left(\times 10^{-3}\right)$ & $\mathrm{MPD}_{\mathrm{s}} / \mathrm{MSD}(\%)$ & $\mathrm{MPD}_{\mathrm{u}} / \mathrm{MSD}(\%)$ \\
\hline NDVI & 0.87 & 7.11 & 0.77 & 6.34 & 10.82 & 89.18 \\
EVI2 & 0.89 & 4.77 & 0.45 & 4.32 & 9.43 & 90.57 \\
\hline
\end{tabular}

The systematic difference between HJ-1 CCDVIs and Landsat-8 OLI-VIs can be minimized using OLS. By taking Landsat-8 OLI-VIs as the dependent variables and $\mathrm{HJ}-1 \mathrm{CCD}-\mathrm{VIs}$ as the response, two linear regression functions for NDVI and EVI2 derived from the four testing sites within six image pairs could be used to rebuild the time-series data in the following phenological parameter extraction.

\subsection{Extraction of phenological parameters using integrated HJ-1 and Landsat-8 VI time-series images}

We compared the smoothed NDVI and EVI2 time-series data at pixel level using S-G filters (Fig. 5).
The phenology stages could be clearly identified from the VI profiles. Most of the noise was successfully eliminated from the VI time-series. The singlecropped rice usually is transplanted during late May to early July, and reaches the heading stage from late August to early September according to the weather and agricultural scheduling. By adding the Landsat- 8 OLI data, the updated VI curves for both NDVI and EVI2 moved to the right.

The transplanting, heading, and maturation dates of the single-cropped rice extracted by HJ-1 VI timeseries and the integrated HJ-1 and Landsat- $8 \mathrm{VI}$ time-series images in Deqing County are presented in Figs. 6-8 separately. For transplanting date, the dates 
extracted by NDVI time-series concentrated in late May to middle June; after integrating Landsat-8 OLI data, with more pixels moved into the 160-169 group. Similarly, the transplanting dates extracted by the EVI2 time-series data of HJ-1 concentrated in late May to early June, and the dates also delayed after integrating Landsat-8 OLI data. Since there were different rice varieties planted in Deqing, the heading dates were more dispersive from early August to early September, but the dates extracted by the NDVI timeseries showed an advancing trend compared with the EVI2 time-series. For maturation dates, both of NDVI and EVI2 showed less difference between the original dataset and the integrated dataset compared with other phenological stages.

The accuracy of the phenological dates extracted as above was evaluated using field-based phenology observations (Table 5; Fig. 9). The estimated dates for each phenological stage were generally within $\pm 6 \mathrm{~d}$ compared with the observations. The differences between the two dates decreased after using the integrated VI time-series as source data for both NDVI and EVI2. Table 5 showed that the root mean square error (RMSE) of the estimated phenological dates using HJ-1 CCD images alone was larger than that of the integrated NDVI and EVI2 images. The RMSE of
Table 5 Root mean square error (RMSE) of the estimated phenological dates compared with the field observed data

\begin{tabular}{ccccc}
\hline VI & Data source & $\begin{array}{c}\text { Transplanting } \\
\text { date }(\mathrm{d})\end{array}$ & $\begin{array}{c}\text { Heading } \\
\text { date }(\mathrm{d})\end{array}$ & $\begin{array}{c}\text { Maturation } \\
\text { date }(\mathrm{d})\end{array}$ \\
\hline NDVI HJ-1 CCD & 9.5 & 11.5 & 5.3 \\
& HJ-1 CCD+ & 5.7 & 10.4 & 4.5 \\
Landsat-8 OLI & & & \\
EVI2 & HJ-1 CCD & 8.4 & 7.4 & 6.4 \\
& HJ-1 CCD+ & 3.1 & 4.3 & 4.2 \\
& Landsat-8 OLI & & & \\
\hline
\end{tabular}

EVI2-derived phenology dates was smaller than that of NDVI in transplanting and heading dates. It showed that after integrating $\mathrm{HJ}-1 \mathrm{CCD}$ and Landsat-8 OLI data, the VI time-series provided a more accurate estimation of rice transplanting, heading, and maturation dates than using single data sources.

\section{Discussion}

Where remote sensing is used as a tool to facilitate the extraction of crop phenology information, "more data" is always the better policy. The crucial point in this practice is to combine the readily available remote sensing data, if possible, and generate a more dense time-series of data. In this study, we took

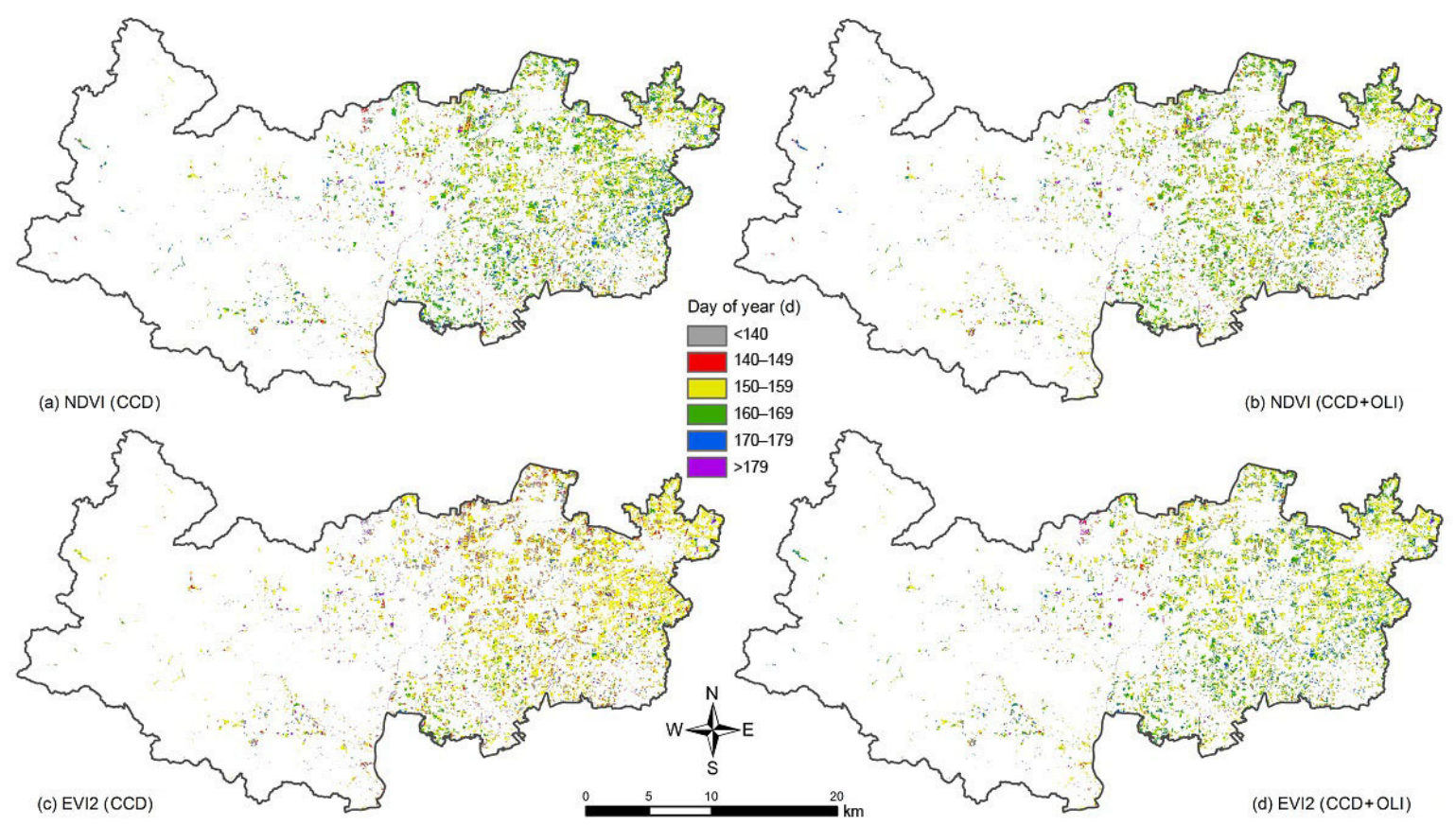

Fig. 6 Transplanting date of rice extracted from NDVI and EVI time-series data in 2013 (a) HJ-CCD derived NDVI time-series; (b) Integrated NDVI time-series; (c) HJ-CCD derived EVI2 time-series; (d) Integrated EVI2 time-series 


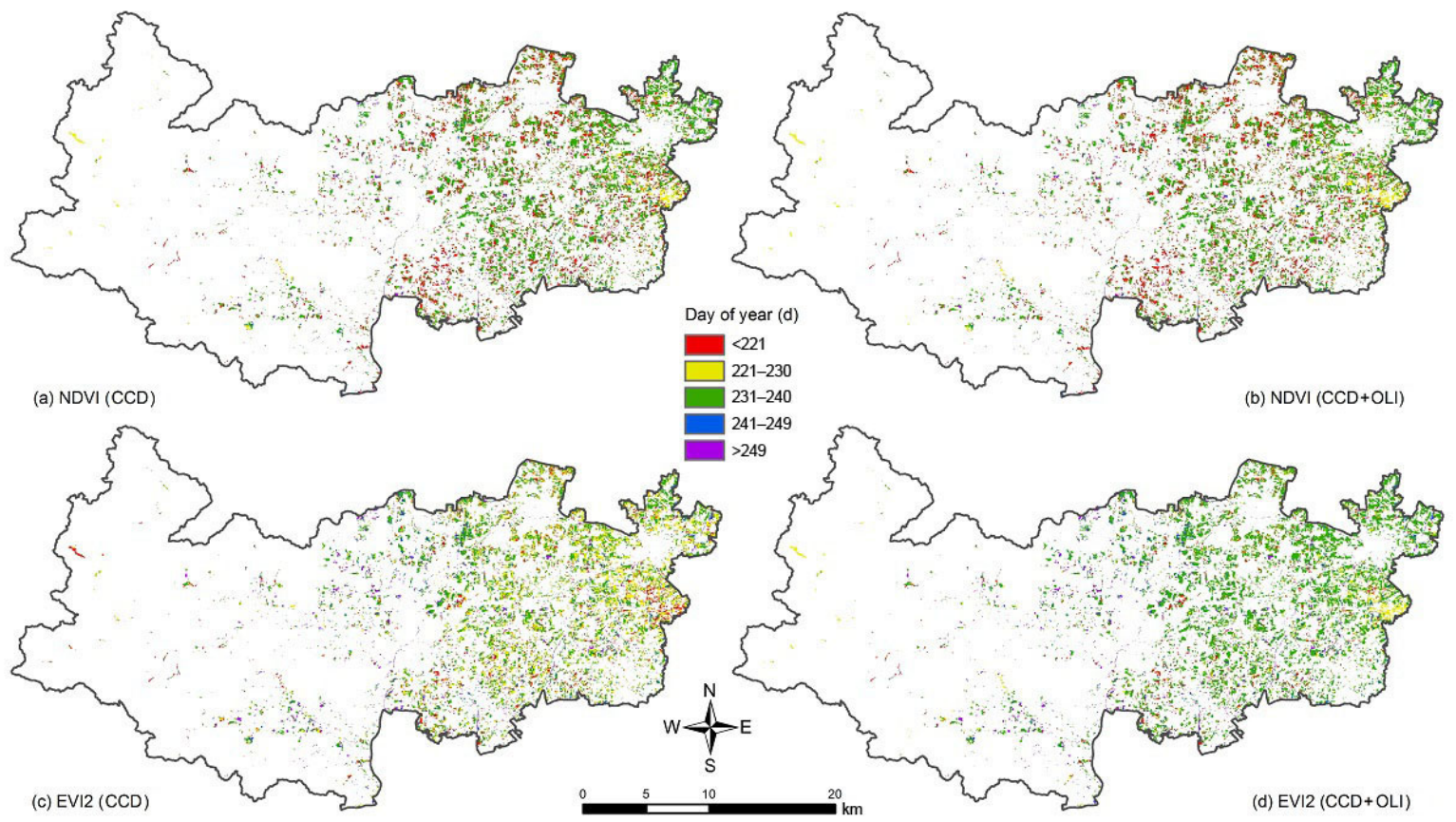

Fig. 7 Heading date of rice extracted from NDVI and EVI2 time-series data in 2013

(a) HJ-CCD derived NDVI time-series; (b) Integrated NDVI time-series; (c) HJ-CCD derived EVI2 time-series; (d) Integrated EVI2 time-series

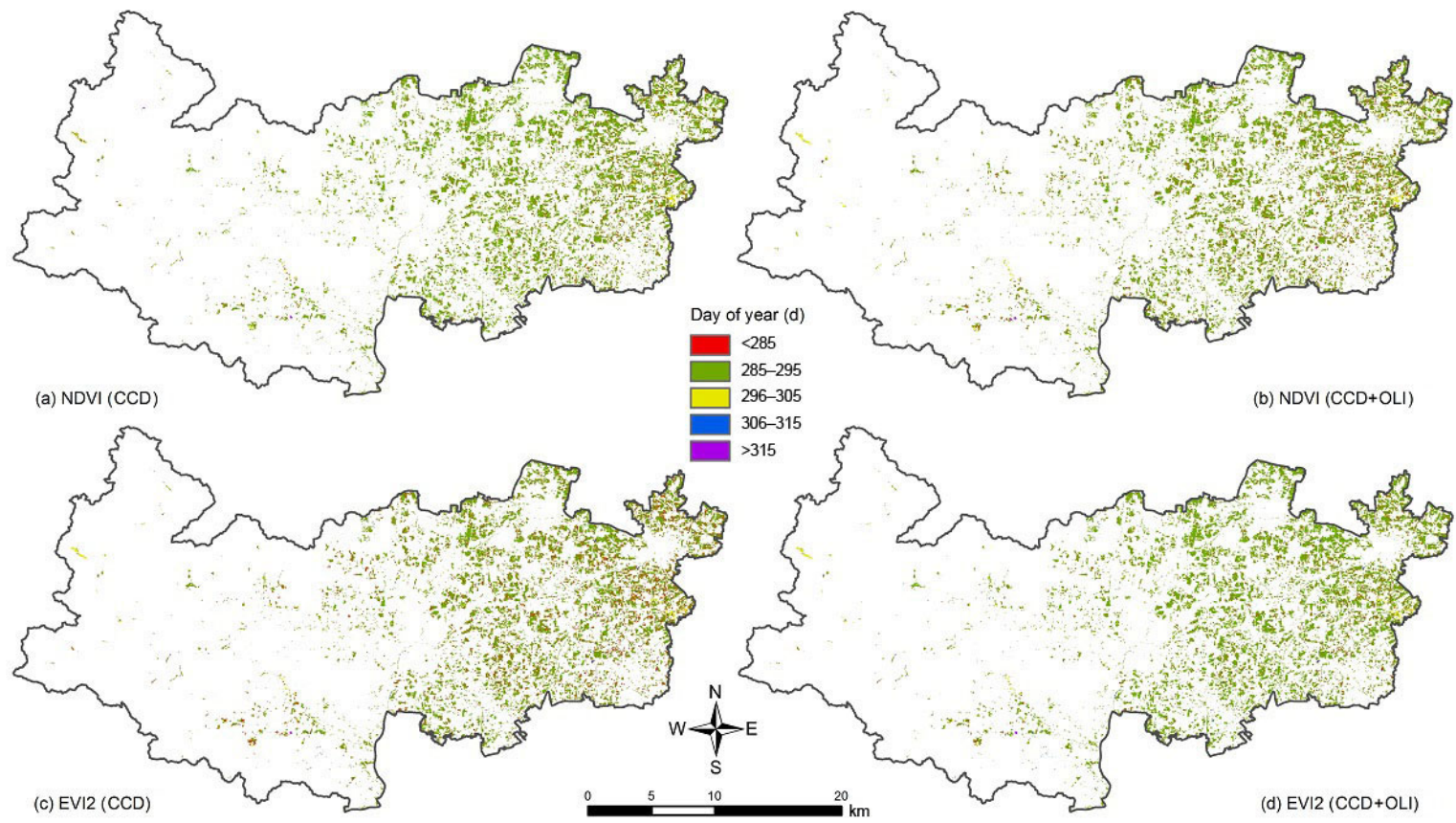

Fig. 8 Maturation date of rice extracted from NDVI and EVI2 time-series data in 2013

(a) HJ-CCD derived NDVI time-series; (b) Integrated NDVI time-series; (c) HJ-CCD derived EVI2 time-series; (d) Integrated EVI2 time-series 

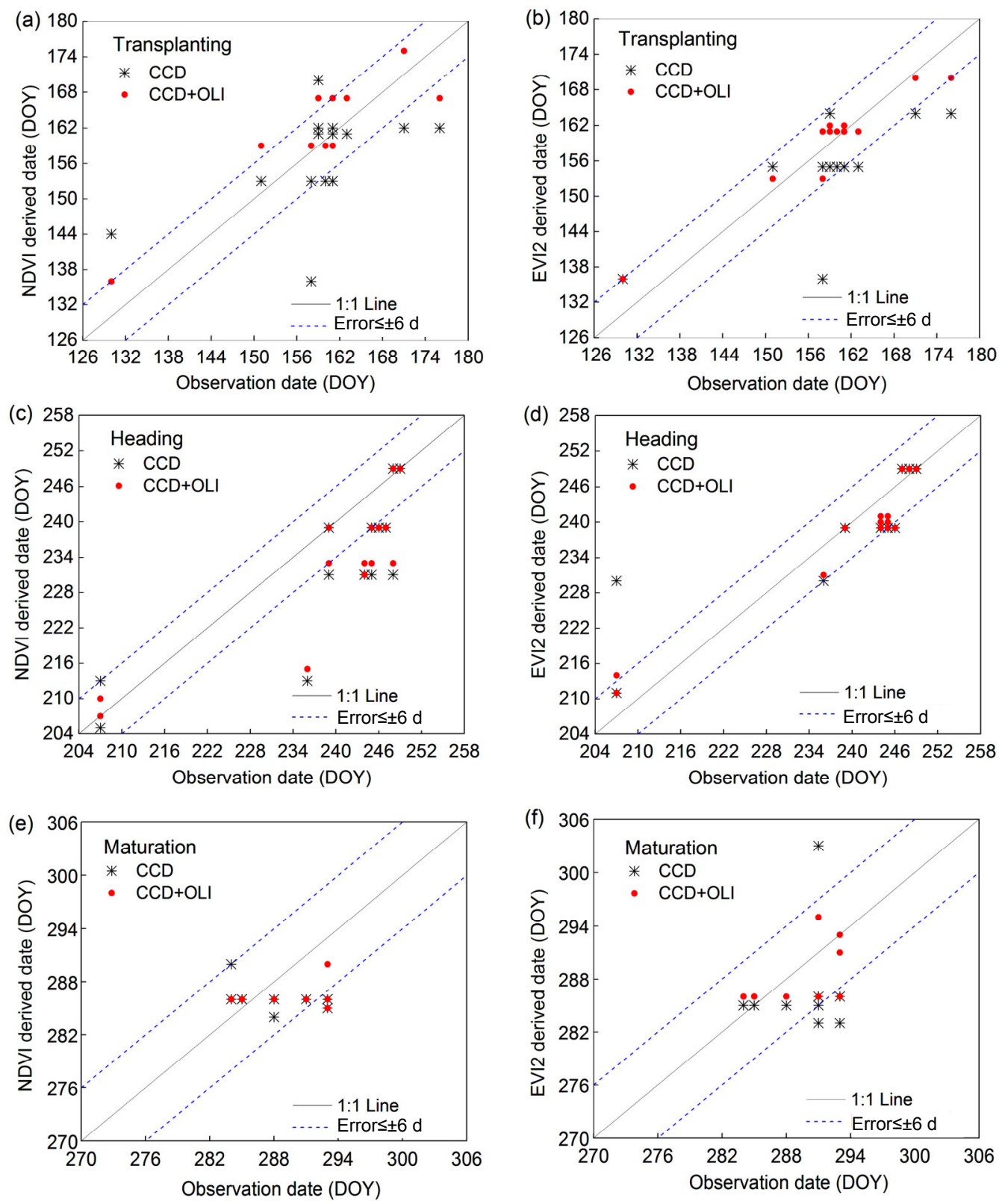

Fig. 9 Key phenology stages (transplanting, heading, and maturation) of rice extracted from time-series data (original and integrated data) compared with the field observed data

(a) Transplanting date extracted by NDVI time-series; (b) Transplanting date extracted by EVI2 time-series; (c) Heading date extracted by NDVI time-series; (d) Heading date extracted by EVI2 time-series; (e) Maturation date extracted by NDVI time-series; (f) Maturation date extracted by EVI2 time-series. DOY: day of year

full advantage of HJ-1 CCD, characterized by its high temporal resolution, and combined this with Landsat-8 OLI data to generate integrated time-series VIs and extract the key phenology information of the singlecropped rice.

We selected NDVI and EVI2 in this study and compared their efficiencies in extracting the phenological information of rice. The comparison of VIs between HJ-1 CCD and Landsat-8 OLI showed slight differences due to the spectral band differences (Teillet and Ren, 2008; Anderson et al., 2011; Li P. et al., 2014). As we had pointed out, the inconsistency between the two sensors could be attributed to systematic and unsystematic differences quantitatively 
described by agreement analysis. The systematic difference between the two sensors could be minimized by OLS, while the unsystematic difference could be effectively attenuated using VI, which could minimize the influence of the environmental factors.

We built the empirical relationships between HJ-1 CCD-VIs and Landsat-8 OLI-VIs datasets at pixel level using OLS. By using the linear regression models, HJ-1 CCD-VIs and Landsat-8 OLI-VIs could be transformed interchangeably. Scatter plots of HJ-1 CCD-VIs versus Landsat-8 OLI-VIs for four testing sites within six image pairs demonstrated that the VIs obtained from HJ-1 CCD and Landsat-8 OLI were highly correlated, and EVI2 had a relatively high $R^{2}$ compared with NDVI (Fig. 4). Not surprisingly, the agreement analysis also showed that EVI2 between the two sensors had significant lower systematic and unsystematic differences compared with NDVI.

To extract the phenological parameters of rice, the S-G filters were applied to smooth the VI timeseries data, and we defined criteria to judge the dates of transplanting, heading, and maturation of the single-cropped rice by considering the VI increment or decrement between consecutive images over a certain period of time according to the field campaign work. Compared with the observed data, EVI2 showed a significantly lower RMSE than NDVI in the estimation of transplanting and heading dates, and this was testified by the relative higher agreement coefficient of EVI2 (Table 4). We noticed that NDVI showed the largest RMSE at heading date, and the heading dates estimated by NDVI advanced compared with the observations (Table 5; Fig. 9). Because NDVI is easily saturated in well-vegetated areas (Huete et al., 2002), it can be seen that NDVI becomes insensitive at high values of leaf area index (LAI) (Gu et al., 2013). Considering that the singlecropped rice usually reaches the peak of LAI between the ear differentiation and early heading stages, the advanced heading date estimated by using NDVI is not unexpected. Compared with NDVI, EVI2 is more robust in capturing the difference in well-vegetated areas and thus has more potential in phenology extraction.

We combined extremum and maximum slope methods in rice phenology estimation. Due to the different methodologies applied in estimating rice phenology in field and remote sensing, an error between the two kinds of estimation is unavoidable.
However, EVI2, especially the integrated EVI2, showed a significant consistency and agreement in phenology dates estimation.

However, it should be noted that the empirical equation built between HJ-1 CCD-VI and Landsat-8 OLI-VI datasets was partially determined by the sample plots and dates of the image pairs. So, there are inevitable uncertainties in the estimation. If extrapolating this kind of integrating methodology and results to other regions or years and considering the variations of environmental factors and vegetation status, necessary re-calibration steps must be taken.

\section{Conclusions}

Accurate extraction of the phenology information of rice in large spatial scale is crucial to agricultural management and related ecological studies. High quality time-series remote sensing data are of critical importance in identifying the key phenology dates as close as possible to the "true" dates. Most of the paddy fields in southern China are influenced by the monsoon climate, and qualified remote sensing data are scarce resources in these regions.

In this study, we showed that by integrating HJ-1 CCD and Landsat-8 OLI data using OLS, the phenological parameters of the single-cropped rice can be estimated more accurately. Two widely used VIs, namely NDVI and EVI2, were adopted, and not surprisingly, the two indices obtained from $\mathrm{HJ}-1$ and Landsat- 8 showed high correlation and agreement $\left(R^{2}>0.87, \mathrm{AC}>0.86\right)$. However, compared with NDVI, EVI2 was more stable and comparable between the two sensors. Compared with the observed data, the integrated VI time-series had a relatively low RMSE, in which EVI2 was superior to NDVI. We also demonstrated the application of phenology extraction of the single-cropped rice in spatial scale in the study area. This work is of general value and can be extrapolated to other regions where qualified remote sensing data are the bottleneck and where complementary data are occasionally available.

\section{Compliance with ethics guidelines}

Jing WANG, Jing-feng HUANG, Xiu-zhen WANG, Meng-ting JIN, Zhen ZHOU, Qiao-ying GUO, Zhe-wen ZHAO, Wei-jiao HUANG, Yao ZHANG, and Xiao-dong SONG declare that they have no conflict of interest. 
This article does not contain any studies with human or animal subjects performed by any of the authors.

\section{References}

Anderson, J.H., Weber, K.T., Gokhale, B., et al., 2011. Intercalibration and evaluation of ResourceSat-1 and Landsat-5 NDVI. Can. J. Remote Sens., 37(2):213-219. [doi:10.5589/m11-032]

Boschetti, M., Stroppiana, D., Brivio, P.A., et al., 2009. Multiyear monitoring of rice crop phenology through time series analysis of MODIS images. Int. J. Remote Sens., 30(18):4643-4662. [doi:10.1080/01431160802632249]

Brown, M.E., de Beurs, K.M., 2008. Evaluation of multisensor semi-arid crop season parameters based on NDVI and rainfall. Remote Sens. Environ., 112(5):2261-2271. [doi:10.1016/j.rse.2007.10.008]

Cai, W.W., Song, J.L., Wang, J.D., et al., 2012. High spatial-and temporal-resolution NDVI produced by the assimilation of MODIS and HJ-1 data. Can. J. Remote Sens., 37(6):612-627. [doi:10.5589/m12-004]

Chen, X.X., Vogelmann, J.E., Chander, G., et al., 2013. Cross-sensor comparisons between Landsat $5 \mathrm{TM}$ and IRS-P6 AWiFS and disturbance detection using integrated Landsat and AWiFS time-series images. Int. J. Remote Sens., 34(7):2432-2453. [doi:10.1080/01431161. 2012.743690]

Cong, N., Piao, S.L., Chen, A.P., et al., 2012. Spring vegetation green-up date in China inferred from SPOT NDVI data: a multiple model analysis. Agric. Forest Meteorol., 165(0):104-113. [doi:10.1016/j.agrformet.2012. 06.009]

Eerens, H., Haesen, D., Rembold, F., et al., 2014. Image time series processing for agriculture monitoring. Environ. Modell. Softw., 53:154-162. [doi:10.1016/j.envsoft.2013. 10.021]

FAOSTAT, 2012. Statistical Database of the Food and Agricultural Organization of the United Nations. Available from http://faostat3.fao.org/browse/Q/*/E [Accessed on Dec. 30, 2014].

Gao, S., Niu, Z., Huang, N., et al., 2013. Estimating the Leaf Area Index, height and biomass of maize using HJ-1 and RADARSAT-2. Int. J. Appl. Earth Obs. Geoinf., 24:1-8. [doi:10.1016/j.jag.2013.02.002]

Gu, Y., Wylie, B.K., Howard, D.M., et al., 2013. NDVI saturation adjustment: a new approach for improving cropland performance estimates in the Greater Platte River Basin, USA. Ecol. Indic., 30(0):1-6. [doi:10.1016/j. ecolind.2013.01.041]

Hird, J.N., McDermid, G.J., 2009. Noise reduction of NDVI time series: an empirical comparison of selected techniques. Remote Sens. Environ., 113(1):248-258. [doi:10.1016/j. rse.2008.09.003]

Huete, A., Didan, K., Miura, T., et al., 2002. Overview of the radiometric and biophysical performance of the MODIS vegetation indices. Remote Sens. Environ., 83(1-2): 195-213. [doi:10.1016/S0034-4257(02)00096-2]
Isobe, T., Feigelson, E.D., Akritas, M.G., et al., 1990. Linear regression in astronomy. Astrophys. J., 364(1):104-113. [doi:10.1086/169390]

Ji, L., Gallo, K., 2006. An agreement coefficient for image comparison. Photogramm. Eng. Remote Sens., 72(7): 823-833. [doi:10.14358/PERS.72.7.823]

Ji, L., Gallo, K., Eidenshink, J.C., et al., 2008. Agreement evaluation of AVHRR and MODIS 16-day composite NDVI data sets. Int. J. Remote Sens., 29(16):4839-4861. [doi:10.1080/01431160801927194]

Jiang, Z.Y., Huete, A.R., Kim, Y., et al., 2007. 2-band enhanced vegetation index without a blue band and its application to AVHRR data. Proc. SPIE 6679, Remote Sensing and Modeling of Ecosystems for Sustainability IV, San Diego, CA, p.667905. [doi:10.1117/12.734933]

Jiang, Z.Y., Huete, A.R., Didan, K., et al., 2008. Development of a two-band enhanced vegetation index without a blue band. Remote Sens. Environ., 112(10):3833-3845. [doi:10. 1016/j.rse.2008.06.006]

Jönsson, P., Eklundh, L., 2004. TIMESAT - a program for analyzing time-series of satellite sensor data. Comput. Geosci., 30(8):833-845. [doi:10.1016/j.cageo.2004.05.006]

Kim, Y., Miura, T., Jiang, Z., et al., 2010. Spectral compatibility of vegetation indices across sensors: band decomposition analysis with Hyperion data. J. Appl. Remote Sens., 4(1):043520. [doi:10.1117/1.3400635]

Lanorte, A., Lasaponara, R., Lovallo, M., et al., 2014. Fisher-Shannon information plane analysis of SPOT/ VEGETATION Normalized Difference Vegetation Index (NDVI) time series to characterize vegetation recovery after fire disturbance. Int. J. Appl. Earth Obs. Geoinf., 26:441-446. [doi:10.1016/j.jag.2013.05.008]

Li, P., Jiang, L.G., Feng, Z.M., 2014. Cross-comparison of vegetation indices derived from Landsat-7 Enhanced Thematic Mapper Plus (ETM+) and Landsat-8 Operational Land Imager (OLI) sensors. Remote Sens., 6(1):310-329. [doi:10.3390/rs6010310]

Li, S.H., Xiao, J.T., Ni, P., et al., 2014. Monitoring paddy rice phenology using time series MODIS data over Jiangxi Province, China. Int. J. Agric. Biol. Eng., 7(6):28-36. [doi:10.3965/j.ijabe.20140706.005]

Mielke, P.W.J., Berry, K.J., 2001. Permutation Methods: a Distance Function Approach. Springer, New York, p.155-238. [doi:10.1007/978-1-4757-3449-2]

Pan, Z., Huang, J., Zhou, Q., et al., 2015. Mapping crop phenology using NDVI time-series derived from HJ-1 A/B data. Int. J. Appl. Earth Obs. Geoinf., 34(0):188-197. [doi:10.1016/j.jag.2014.08.011]

Panda, S.S., Ames, D.P., Panigrahi, S., 2010. Application of vegetation indices for agricultural crop yield prediction using neural network techniques. Remote Sens., 2(3): 673-696. [doi:10.3390/rs2030673]

Peng, D.L., Huete, A.R., Huang, J.F., et al., 2011. Detection and estimation of mixed paddy rice cropping patterns with MODIS data. Int. J. Appl. Earth Obs. Geoinf., 13(1): 13-23. [doi:10.1016/j.jag.2010.06.001] 
Pyongsop, R.I., Ma, Z.B., Qi, Q.W., et al., 2010. Cloud and shadow removal from Landsat TM data. J. Remote Sens., 14(3):534-545.

Rawlings, J.O., Pantula, S.G., Dickey, D.A., 1990. Applied regression analysis: a research tool. J. Oper. Res. Soc., 41(8):782-783. [doi:10.2307/2583482]

Rouse, J.W., Haas, R.H., Schell, J.A., et al., 1974. Monitoring the vernal advancement of retrogradation of natural vegetation. Technical Report No. E74-10113, Texas AM University, College Station, TX, USA.

Sakamoto, T., Yokozawa, M., Toritani, H., et al., 2005. A crop phenology detection method using time-series MODIS data. Remote Sens. Environ., 96(3-4):366-374. [doi:10. 1016/j.rse.2005.03.008]

She, B., Huang, J.F., Guo, R.F., et al., 2015. Assessing winter oilseed rape freeze injury based on Chinese HJ remote sensing data. J. Zhejiang Univ.-Sci. B (Biomed. \& Biotechnol.), 16(2):131-144. [doi:10.1631/jzus.B1400150]

Shi, J.J., Huang, J.F., Zhang, F., 2013. Multi-year monitoring of paddy rice planting area in Northeast China using MODIS time series data. J. Zhejiang Univ.-Sci. B (Biomed. \& Biotechnol.), 14(10):934-946. [doi:10.1631/ jzus.B1200352]

Sprent, P., Dolby, G.R., 1980. The geometric mean functionalrelationship. Biometrics, 36(3):547-550. [doi:10.2307/ 2530224]

Steven, M.D., Malthus, T.J., Baret, F., et al., 2003. Intercalibration of vegetation indices from different sensor systems. Remote Sens. Environ., 88(4):412-422. [doi:10.1016/j.rse.2003.08.010]

Teillet, P.M., Ren, X.M., 2008. Spectral band difference effects on vegetation indices derived from multiple satellite sensor data. Can. J. Remote Sens., 34(3):159-173. [doi:10.5589/m08-025]

Valsami, G., Macheras, P., 1995. The geometric mean functional relationship approach to linear regression in pharmaceutical studies: application to the estimation of binding parameters. Pharm. Pharmacol. Comm., 1(12): 551-554. [doi:10.1111/j.2042-7158.1995.tb00377.x]

Wang, J., Huang, J., Zhang, K., et al., 2015. Rice fields mapping in fragmented area using multi-temporal HJ-1A/B CCD images. Remote Sens., 7(4):3467-3488. [doi:10.3390/rs70403467]

Wu, W.B., Yang, P., Tang, H.J., et al., 2010. Characterizing spatial patterns of phenology in cropland of China based on remotely sensed data. Agric. Sci. China, 9(1):101-112. [doi:10.1016/S1671-2927(09)60073-0]

Xie, Y.C., Sha, Z.Y., Yu, M., 2008. Remote sensing imagery in vegetation mapping: a review. J. Plant Ecol., 1(1):9-23. [doi:10.1093/jpe/rtm005]

Xin, J., Yu, Z., van Leeuwen, L., et al., 2002. Mapping crop key phenological stages in the north China plain using NOAA time series images. Int. J. Appl. Earth Obs.
Geoinf., 4(2):109-117. [doi:10.1016/S0303-2434(02)000 07-7]

You, X.Z., Meng, J.H., Zhang, M., et al., 2013. Remote sensing based detection of crop phenology for agricultural zones in China using a new threshold method. Remote Sens., 5(7):3190-3211. [doi:10.3390/rs5073190]

Yu, F.F., Price, K.P., Ellis, J., et al., 2003. Response of seasonal vegetation development to climatic variations in eastern central Asia. Remote Sens. Environ., 87(1):42-54. [doi:10.1016/S0034-4257(03)00144-5]

Zhang, L.W., Huang, J.F., Guo, R.F., et al., 2013. Spatiotemporal reconstruction of air temperature maps and their application to estimate rice growing season heat accumulation using multi-temporal MODIS data. $J$. Zhejiang Univ.-Sci. B (Biomed. \& Biotechnol.), 14(2): 144-161. [doi:10.1631/jzus.B1200169]

\section{中文概要}

\section{题 目: 基于环境减灾卫星及 Landsat-8 卫星的植被指数 时间序列的水稻物候期提取研究}

目 的: 鉴于中国南方地区单季稻种植区在关键生育期较 难获得清晰影像的情况, 利用相互校准方法并结 合 HJ-1 CCD 和 Landsat-8 OLI 传感器, 生成时间 分辨率更高的植被指数时间序列数据, 并比较不 同植被指数在提取水稻物候期中的差异。

创新点: 本文通过传感器相互校准获得了具有更高时间分 辨率的植被指数时间序列数据, 同时研究了不同 植被指数在提取水稻物候期中的有效性, 从而提 高了水稻物候期提取的精度。

方 法: 利用最小二乘法对 HJ-1 CCD 和 Landsat-8 OLI 传 感器提取的植被指数 (EVI2 和 NDVI) 进行相互 校准, 验证了不同传感器可互补使用; 利用一致 性分析方法, 对比不同植被指数在提取单季稻物 候期中的有效性; 通过极值法和最大斜率法提取 研究区单季稻的移栽期、抽穗期和成熟期; 将利 用两传感器相结合形成的新植被指数时间序列 数据得到的水稻物候期提取结果, 与用单一传感 器得到结果进行对比, 分析水稻物候期提取精度。

结 论: 基于环境减灾卫星及 Landsat-8 卫星融合后得到 的植被指数时间序列数据可以有效地提高南方 单季稻物候期提取的精度, EVI2 的提取效果优于 NDVI，极值法和最大斜率法结合提取的单季稻 物候期结果与野外调查及农气站统计结果较为 吻合, 可以很好地应用于实际业务中。

关键词: 物候提取; 相互校准; 植被指数; HJ-1 CCD; Landsat-8 OLI 